\title{
The Impact Analysis of the Distributed Generation Outage Loss to Customers Based on the Probabilistic Production Simulation
}

\author{
Du Zhengdong ${ }^{1, a}$, Liu Dunnan ${ }^{2, b}$, Ying Yuhang ${ }^{2, c}$, Yu Dan ${ }^{1, d}$ and Weng Hua ${ }^{1, e}$ \\ ${ }^{1}$ State Power Zhejiang Economic Research Institute, HangZhou, China; \\ ${ }^{2}$ School of Economics and Management, North China Electric Power University, Beijing, China \\ ahzdzd@163.com, ${ }^{\mathrm{b}}$ liudunnan@163.com, ${ }^{\mathrm{c}}$ oliviayyh@126.com, ${ }^{\mathrm{d}}$ 89217948@qq.com, ${ }^{\mathrm{e}}$ wenghua198 \\ 6@163.com
}

Keywords: Probabilistic production simulation, distributed generation, reliability, customer outage cost.

\begin{abstract}
With the growing shortage of energy, the requirement of environmental protection is constantly improving, and distributed generation is increasing in the grid. The increase of permeability of distributed power will affect the electricity reliability, which affects customer outage costs. This paper introduces how to figure out outage costs function by probabilistic production simulation. illustrative example is taken to confirm that the change of outage costs at different penetration rate is calculated by stochastic production simulation.
\end{abstract}

\section{Introduction}

The distributed generation is distributed in different parts of the distribution network, can supply power to load in real time, especially when it goes wrong on grid. And most of the distributed generation use renewable clean energy, which is harmonious with the current environmental protection and sustainable development policy. Moreover, it is helpful for the realization of energy conservation and emissions reduction goal.

But distributed generation also has its disadvantages, due to the volatility of intermittent power supply, utilization duration is less than the normal supply, and more units are needed at the same generation. Because of the forced outage rate, the increase of intermittent power supply capacity will affect total loss of load probability of the system. The loss of load probability is an important parameter affecting the power reliability, thus to study the effect of distributed generation on customer outage costs is of great significance.

Stochastic production simulation is a powerful tool for power market to do electric energy cost analysis, price forecasting and power management. Through the stochastic production simulation, reliability indexes such as loss of load probability and expected loss of energy can be calculated to analyze the reliability of power system. This paper studies the probabilistic production simulation method and the customer outage costs calculation method, and then introduces how to figure out outage costs function by probabilistic production simulation. Finally, an illustrative example is taken to confirm that the change of outage costs at different penetration rate is calculated by stochastic production simulation.

\section{Stochastic production simulation}

Stochastic production simulation of power system is a kind of algorithm, which can calculate each power plant generation, production cost and reliability index by optimizing production situation of units, considering random generator faults and random load.

Stochastic production simulation is one of the basic anarchistic tools for traditional power system planning and operation. In recent years, more new algorithms of stochastic production simulation appear, to adapt to the requirements of modern power system development. Stochastic production simulation has become an important tool for power system to make analysis of technical economic. 
When making existing power system operation plan, stochastic production simulation can provide important data to deal with a lot of running problems. Such as according to economic index and reliability index of every run time, generator set maintenance plan can be further optimized and adjusted; in terms of technical and economic indexes of power system operation in each period, to optimize electric power and electric quantity switching scheme with other electric system, etc.

\section{Customer outage costs}

Outage cost is the economic loss given to the customer and the society, due to the instability of power supply, or power outage caused by electric power system fault.

The power outage costs data calculated can provide a reference for power planning stage.The ratio of GDP to electric power method refers to the ratio of gross domestic product to electricity consumption of an area within a certain period of time, and its unit is yuan $/ \mathrm{kWh}$. It symbolizes a region per unit of electricity generated economic benefits in a year, is to use a monetary value to a social measure of electricity, on the macro perspective, can be approximately estimated power loss.

On the basis of the statistics, approximate mathematical model can be set up. To facilitate the analysis, and do not break general, assume that GDP and electricity use according to the annual growth obey exponential model, there are:

$$
\begin{aligned}
& G(\mathrm{t})=G(0) e^{\alpha t} \\
& E(\mathrm{t})=E(0) e^{\beta t} \\
& R(\mathrm{t})=\frac{G(0)}{\mathrm{g}(0)} \cdot e^{(\alpha-\beta) t}
\end{aligned}
$$

$\mathrm{G}(\mathrm{t})$ and $\mathrm{G}(0)$ is respectively t-year and initial GDP value, the unit is a hundred million yuan. $\mathrm{E}(\mathrm{t})$ and $\mathrm{E}(0)$ is respectively t-year and initial power consumption, the unit is a hundred million kWh. $\alpha$ and $\beta$ is respectively average annual growth rate of GDP and electricity consumption, the unit is $1 / \alpha$. T-year ratio of GDP and electric power method is $\mathrm{R}(\mathrm{t})$.

\section{Algorithm implementation}

\section{Load duration curve of probabilistic production simulation}

The different load and load duration are needed. Load and duration are set as abscissa and ordinate of the planar reference frame respectively. Then, the load duration curve is finished after drawing points, which is shown in fig.1.

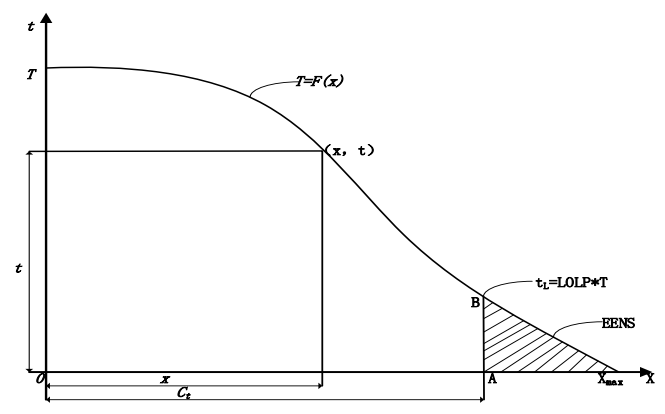

Fig.1 Load duration curve

In which, $\mathrm{X}$-axis and $\mathrm{Y}$-axis show load and load duration respectively. $T$ is simulation cycle, and is determined by the specific situation. Point $\left(X_{t}\right)$ on the curve is the duration $(t)$ when system load is greater than or equal to the load, which is $t=F(X)$.

Divide the formula above by $T$, the formula following is got:

$$
P=f(x)=F(x) / T
$$

In the figure, $P$ could be seem as the probability that the system load is greater than or equal to the load. And the total load can be figured out by integral.

$$
E_{s}=\int_{0}^{x_{\max }} F(x) d x
$$


Similarly, after divided by $T$, the expectation value of the load is got.

$\overline{\mathrm{x}}=\int_{0}^{x_{\max }} f(x) d x$

Suppose that $C_{s}$ is the running generator capacity of a system in the simulation period. With point $B, \boldsymbol{t}_{\boldsymbol{L}}$ is the duration when system load is greater than $C_{s}$. Similarly, the loss of load probability is figured out by formula(8).

$$
t_{L}=F\left(C_{s}\right)
$$

$$
L O L P=\frac{t_{L}}{T}=f\left(C_{s}\right)
$$

Suppose the system load is greater than generator capacity. The generator cannot provide enough load shown in the shaded area, expected energy not supplied can be figured out by integral.

$$
\text { EENS }=\int_{C_{s}}^{x_{\max }} F(x) d x=T \int_{C_{s}}^{x_{\max }} f(x) d x
$$

\section{Equivalent load duration curve}

Power unit has the probability of outage, so the random outage should be considered while calculating the reliability index. Then the original load duration curve is revised, to get the equivalent curve that has considered random outage. Introduction of convolution is used to modify the curve, which is shown in fig.2. $f^{0}$ is the original curve, and suppose $C_{\mathrm{t}}$ is the capacity of the first generator under load, and $p_{1}$ is the available rate. Then forced outage rate is $q_{1}=1-p_{1}$.

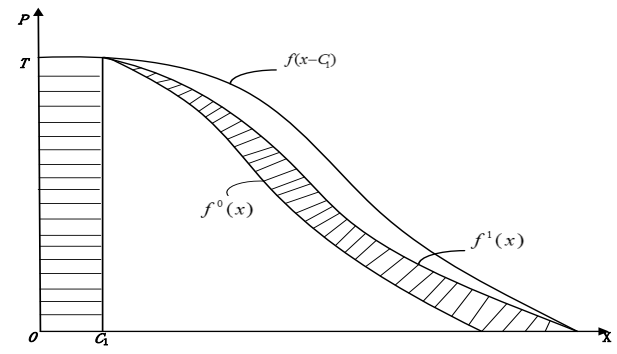

Fig. 2 the formation of equivalent load duration curve

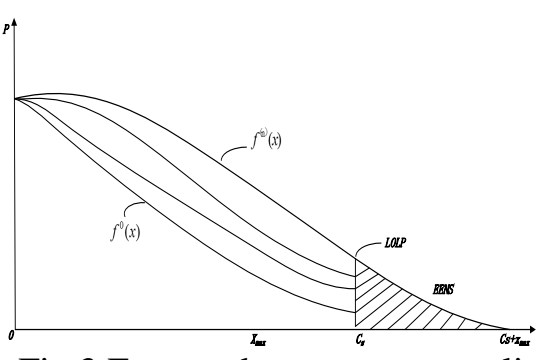

Fig.3 Expected energy not supplied

During the normal running, the load of units is $f^{0}(x)$. While the first unit brakes down, system load would be borne by other generators, which is to say that all the units bear the load of $x_{\max }+C_{1}$ together. So that the curve $f^{0}(x)$ translate right, forming the curve $f^{(0)}\left(x-C_{1}\right)$.

The available rate and forced outage rate of the first generator unit are $p_{1}$ and $q_{1}$ respectively, so the equivalent load duration curve is figured out by convolution as follows when the random outage is considered.Similarly, the convolution of the number I generator can be figured out.

$$
\begin{aligned}
& f^{(1)}(x)=p_{1} f^{(0)}(x)+q_{1} f^{(0)}\left(x-C_{1}\right) \\
& f^{(i)}(x)=p_{i} f^{(i-1)}(x)+q_{i} f^{(i-1)}\left(x-C_{i}\right)
\end{aligned}
$$

In the formula, $C_{i}$ is the rated capacity of generator $\mathrm{i}, p_{i}$ is the available rate, outage rate is $q_{i}=1-p_{i}$. Suppose there are $\mathrm{n}$ units, after operation and convolution calculation, the final equivalent load duration curve $f^{(\mathrm{n})}(x)$ is got. And the largest equivalent load is $x_{\max }+C_{s}$. Accordingly, the EENS and LOLP are figured out.

$$
\begin{aligned}
& \text { EENS }=T \int_{C_{s}}^{x_{\max }+C_{s}} f^{(n)}(x) d x \\
& L O L P=f^{(\mathrm{n})}\left(C_{s}\right) \\
& t=T^{*} L O L P
\end{aligned}
$$

Moreover, the time of outage duration is $t=T * L O L P$, which can show power shortage more intuitively, and analyze the power supply reliability more efficiently.

\section{Case study}

In this case, Suppose the total capacity is $10000 \mathrm{MW}$, with large thermal-power units of $7000 \mathrm{MW}$ and small thermal-power of 3000MW. The annual maximum load and minimum load are $8300 \mathrm{MW}$ and $6600 \mathrm{MW}$ respectively. The probability of system load loss is $0.12 \%$ before the 
connection. Collect the annual load and load duration data of 8760 hours, duration load curve and the function is got.

Table 1 System parameters before the connection with intermittent power supply

\begin{tabular}{|c|c|c|c|c|}
\hline Number & Unit type & Cpacity & Number of units & Forced outage rate \\
\hline 1 & Coal-fired unit & 1000 & 4 & $8.00 \%$ \\
\hline 2 & Coal-fired unit & 600 & 2 & $4.10 \%$ \\
\hline 3 & Coal-fired unit & 300 & 6 & $1.90 \%$ \\
\hline 4 & Nuclear power & 1000 & 1 & $8.50 \%$ \\
\hline 5 & Hydropower & 200 & 10 & $1.00 \%$ \\
\hline
\end{tabular}

With the increase capacity of distributed power supply access, the influence is measured, and the proportion of distributed generation in total installed capacity is defined. Take the reference of other paper, the forced outage rate of distributed intermittent power supply is $1.9 \%$. The ratio of distributed generation to normal is $3: 1$. And set penetration rate of $3 \%, 6 \%, 9 \%, 12 \%$ into matlab respectively to calculate loss of load probability. Then calculate the outage time and lack of supply. According to power consumption and economy, the ratio of output value to power consumption is estimated to be 7 yuan/MWh. Outage cost with different penetration rate of distributed power supply can be figured out.

Table 2 The influence of distributed power on outage loss to users

\begin{tabular}{|c|c|c|c|c|c|c|c|}
\hline $\begin{array}{c}\text { penetration } \\
\text { rate }\end{array}$ & Generation & $\begin{array}{c}\text { Loss of load } \\
\text { probability }\end{array}$ & $\begin{array}{c}\text { Outage } \\
\text { time }\end{array}$ & $\begin{array}{c}\text { Lack of } \\
\text { supply }\end{array}$ & $\begin{array}{c}\text { ratio of output to } \\
\text { consumption } \\
\text { (Yuan/MWh) }\end{array}$ & $\begin{array}{c}\text { Outage cost } \\
\text { (Yuan })\end{array}$ & $\begin{array}{c}\text { New outage } \\
\text { cost (Yuan) }\end{array}$ \\
\hline $3 \%$ & 300 & $0.0875 \%$ & 7.67 & 31809.75 & 7000 & 222668250 & 18831372 \\
\hline $6 \%$ & 600 & $0.0950 \%$ & 8.33 & 34550.84 & 7000 & 241855891 & 38019013 \\
\hline $9 \%$ & 900 & $0.1000 \%$ & 8.76 & 36354.00 & 7000 & 254478000 & 50641122 \\
\hline $12 \%$ & 1200 & $0.1100 \%$ & 9.64 & 39989.40 & 7000 & 279925800 & 76088922 \\
\hline
\end{tabular}

\section{Conclusion}

Because of the volatility, use duration of intermittent power generation is less than normal, and units needed is more. With the increase of its capacity, the loss-of-load probability increase, then outage time and lack of supply raise. To get outage cost, make economic transformation of lack of supply by ratio of output to consumption. There is more outage cost with the higher penetration rate. Therefore, it is necessary to analyze the limit of power consumption reliability further, which could limit the penetration rate of distributed power.

\section{References}

[1] ZHANG Qian, ZHU Xue-ling, HUANG Jun-hui, et al. Mathematical model and forecasting method of load duration curve, J. Electric Power, 2009, 09:49-53.

[2] XIE Chu, ZHANG Yan, HUANG Yi-chao, Application of Reliability Cost-Benefit Analytical Method in Power Grid, J. Electric Power, 2013, 05:106-110.

[3] NIE Yong-hui, LI Tian-yun, GUAN Xiao-hui, CHU Zhuang, Power system probabilistic production simulation including wind farms, J. Power System Protection and Control, 2013,14:102-107.

[4] ZOU Bin, LI Dong, Power System Probabilistic Production Simulation With Wind Generation Based on Available Capacity Distribution,J. Proceedings of the CSEE, 2012,07:23-31+187.

[5] YU Ruo-ying, GAO Shan, Applications of probabilistic production simulation in power system, J. Power System Protection and Control, 2012,11:149-155. 
[6] ZHANG Hong-yu, FANG Xin, LI Bi-hui, et al. Probabilistic production simulation of power systems with large-scale wind and photovoltaic generation, J. Electric Power, 2012,06:73-76.

[7] Wang Xifan, Wang Xiuli, PROBABILISTIC PRODUCTION SIMULATION METHOD AND ITS APPLICATION, J. Automation of Electric Power Systems, 2003,08:10-15+31.

[8] Guo Xuyang, Probabilistic Production Simulation of Power System With Grid-Connected Photovoltaic Generation, D. Chongqing University,2013. 